\title{
Effect of Polystyrene Treatment on the Efficiency and Stability of Fully Printable Mesoscopic Perovskite Solar Cells With Carbon Electrode
}

Kyong Su Sonu ( $\sim$ ks.sonu0301@ryongnamsan.edu.kp )

Kim II Sung University https://orcid.org/0000-0003-4788-7764

Pyol Kim

Kim II Sung University

\section{Song Guk Ko}

Kim II Sung University

Hak Son So

Kim II Sung University

Jin Hyok Ri

Kim II Sung University

Kwon II Ryu

Kim II Sung University

\section{Research Article}

Keywords: printable mesoscopic perovskite solar cells, polystyrene, carbon electrode, hole conductor free

Posted Date: March 16th, 2021

DOI: https://doi.org/10.21203/rs.3.rs-295668/v1

License: (1) This work is licensed under a Creative Commons Attribution 4.0 International License.

Read Full License 


\section{Abstract}

Hole conductor-free, fully printable mesoscopic perovskite solar cells with carbon electrode (PM-PSCs) have a good commercialization prospect because of low-cost production and high power conversion efficiency (PCE). Currently, the problem of improving the stability of perovskite solar cells (PSCs) is very important for commercialization. Interfacial engineering using polymers is an effective method to improve the efficiency and stability of PSCs. We prepared PM-PSCs by treatment with the toluene solution containing PS on the carbon electrode of the PM-PSCs, which would improve the charge transfer and greatly suppressed charge recombination in polystyrene (PS)-treated PM-PSCs, and also could greatly prevent degradation of perovskite into $\mathrm{Pbl}_{2}$. The PS-treated PM-PSCs showed higher stability to light and moisture than the control, and the PCE was improved from $11.31 \%$ (control) to $14.03 \%$.

\section{Introduction}

The development and use of clean and renewable energy resources is important to solve the energy production by fossil fuels, the environmental pollution resulting from them, global warming problems and to meet future energy needs. In 2002, the solar energy absorbed by the earth's surface for an hour was more than the energy consumed by the whole world for a year [1]. Because of this, if the solar energy can be converted into electricity using low-cost and high efficiency solar cells, it will be possible to protect the ecological environment and obtain the energy we need effectively.

Among all the PV technologies, perovskite solar cells (PSCs) are one of the hot spots in solar cells research due to their low cost and high power conversion efficiency (PCE) [2][3]. The PCE of PSCs has grown rapidly in the last decade, reaching $25.2 \%$ power conversion efficiency [4]. This rapid increase of PCE in PSCs compared to silicon solar cells is mainly related to the excellent photoelectric properties of metal halide perovskites and the low charge carrier recombination [5-9]. Although the PCE of PSCs is improving rapidly, several challenges remain until commercialization. At present, there is a focus on the stability [10-13], hysteresis [14-16], lead-free perovskite [17-19], cost-effective and scalable fabrication processes for PSCs [20-24].

In general, the grain boundaries and surfaces of perovskite films are low in crystallinity, incomplete coordination of atoms, and large surface area can lead to easy degradation by moisture and heat. In order to improve the stability of PSCs, efficient interfacial modification and encapsulation are necessary to passivate the perovskite crystal surface and to prevent the degradation of perovskite by external stresses without negatively affecting the photoelectric properties of perovskite. Polymers are effective materials that can improve the PCE and stability of PSCs due to their good mechanical properties, low cost, etc. For example, polymers such as polymethylmethacrylate [25][26], ethyl cellulose [27], polyethylene glycol [28], and polyethylene imine [29] have been used to improve the stability of PSCs. Recently, Saraf et al. reported a polystyrene (PS) incorporation into $\mathrm{CH}_{3} \mathrm{NH}_{3} \mathrm{Pbl}_{3}$ precursor for stable PSCs even after a continuous irradiation of 1 sun intensity for 1000h [30]. Poly(3,4-ethylene 
transporter in PSCs, contains a PS polymer, which is considered an excellent material that not only forms a mechanically robust hole transporter layer, but also reduces the use of conjugated polymers to increase stability [31]. This hydrophobic PS can greatly improve the stability of perovskite solar cells by preventing the corrosion of perovskite without reducing the photoelectric properties of perovskite.

The structure of PM-PSCs consists of a porous three-layer structure composed of $\mathrm{TiO}_{2}$ layer, $\mathrm{ZrO}_{2}$ layer and carbon layer, so the surface area of perovskite can be relatively large and many surface defects can be present due to the formation of perovskite crystals by penetrating the perovskite precursor solution from the carbon layer. The hydrophobic carbon electrode, of course, enhances the corrosion resistance to moisture and light, but the many existing surface defects and the micropores present inside the polycrystalline film are hazardous elements that can promote moisture and heat corrosion. However, to our knowledge, there are few studies on the use of polymers to improve the efficiency and stability of PMPSCs. Furthermore, Furthermore, the application of PS for PSCs with hole conductor has been carried out [30][31][35], but no studies have been conducted on PM-PSCS.

In the present study, we first penetrated the perovskite precursor through the carbon counter electrode and crystallized, and subsequently treated with the toluene solution containing PS on it to complete PM-PSCs and improve its PCE and photostability. Electrochemical impedance spectroscopy (EIS) showed that the charge transfer resistance of $1 \mathrm{wt} \%$ PS treated PM-PSCs was effectively reduced and the charge recombination resistance of PM-PSCs was greatly improved, resulting in an improved shirt-circuit current density (Jsc), open-circuit voltage (Voc), fill factor (FF), and PCE, respectively. In photostability test of maximum power-point tracking under $100 \mathrm{~h}$ continuous illumination of 1 sun intensity at $25^{\circ} \mathrm{C}$ and $60 \%$ of humidity, the PCE of PS-treated PM-PSCs without encapsulation was retained $90 \%$ of the initial PCE.

\section{Experimental Section}

\subsection{Materials}

All the chemicals were directly used without any further purification: Lead iodide $\left(\mathrm{Pbl}_{2}, 99.999 \%\right.$, SigmaAldrich), lead cloride ( $\mathrm{PbCl}_{2}, 99.999 \%$, Sigma-Aldrich), methylammonium iodide(MAl, 99\%, Jingge, Wuhan), N,N-dimethylformamide (DMF, analytical, Aladdin), polystyrene (PS, Mw-180000, Sigma-Aldrich), titanium-butoxide(99.0\%, Aladdin). The other chemical reagents were of analytical grade.

\subsection{Device Fabrication}

PM-PSCs were prepared by coating $\mathrm{TiO}_{2}$ compact layer on fluorine doped tin oxide (FTO) and subsequently screen-printing the $\mathrm{TiO}_{2}, \mathrm{ZrO}_{2}$ and carbon layers, and then penetrating the perovskite precursor solution from the carbon layer, as shown in Fig. 1a. FTO substrates were laser etched to form two separate electrodes, ultrasonic rinses with detergents, distilled water, and ethanol three times. After drying, the cleaned FTO substrates were immersed in $0.2 \mathrm{M} \mathrm{TiCl}_{4}$ aqueous solution, kept at $70^{\circ} \mathrm{C}$ for $1 \mathrm{~h}$, washed with deionized water, and were sintered at $500^{\circ} \mathrm{C}$ for 30 min to form compact $\mathrm{TiO}_{2}$ layers. 
$\mathrm{ZrO}_{2}$ and carbon pastes except of $\mathrm{TiO}_{2}$ paste were prepared using our previous method [32]. $\mathrm{TiO}_{2}$ paste was prepared as following: $5 \mathrm{~mL}$ of titanium-butoxide was placed in $100 \mathrm{~mL}$ of distilled water and stirred at $1000 \mathrm{rpm}$ for $30 \mathrm{~min}$, followed by adding dropwise of hydrogen peroxide(35\%) at a molar ratio of 20/1 (hydrogen peroxide/titanium-butoxide). After overnight stirring, it was hydrothermallized at $200^{\circ} \mathrm{C}$ for $12 \mathrm{~h}$ and vacuum dried at $40^{\circ} \mathrm{C}$ to obtain $\mathrm{TiO}_{2}$ powder. Then $\mathrm{TiO}_{2}$ powder, terpineol and ethyl cellulose were mixed at a mass ratio of $1 / 5 / 0.5$ and ball-milled for $6 \mathrm{~h}$ to prepare $\mathrm{TiO}_{2}$ paste. $\mathrm{ZrO}_{2}$ paste was prepared by mixing $1.5 \mathrm{~g}$ of $\mathrm{ZrO}_{2}$ (size: $20 \mathrm{~nm}$ ), $0.35 \mathrm{~g}$ of ethyl cellulose and $60 \mu \mathrm{L}$ of acetylacetone with $20 \mathrm{~mL}$ of terpineol. Carbon paste was prepared by mixing $3 \mathrm{~g}$ of graphite (size: $15 \mathrm{~nm}$ ), $1 \mathrm{~g}$ of carbon black (size: 30 $\mathrm{nm}$ ) and $1 \mathrm{~g}$ of ethyl cellulose with $10 \mathrm{~mL}$ of terpineol. $\mathrm{TiO}_{2}$ paste was screen-printed on the $\mathrm{TiO}_{2}$ compact layer and sintered at $500^{\circ} \mathrm{C}$ for $30 \mathrm{~min}$ to form a mesoporous $\mathrm{TiO}_{2}$ film (thickness: $0.5 \mathrm{Z}$ ). The mesoporous $\mathrm{TiO}_{2}$ film substrate was immersed in $40 \mathrm{mM} \mathrm{TiCl}_{4}$ aqueous solution at $70^{\circ} \mathrm{C}$ for $30 \mathrm{~min}$, removed and washed with deionized water and dried. Then, $\mathrm{ZrO}_{2}$ and carbon pastes were screen-printed and sintered at 500 and $400^{\circ} \mathrm{C}$ for $30 \mathrm{~min}$, respectively, to form $\mathrm{ZrO}_{2}$ layers (thickness : $1 \mathrm{Q}$ ) and carbon layers (thickness : 108).

The perovskite precursor solution was prepared by dissolving $\mathrm{MAI}, \mathrm{PbI}_{2}$, and $\mathrm{PbCl}_{2}$ in $\mathrm{DMF}$ at a molar ratio 4:3:1. We used toluene as the solvent of PS solution as it did not degrade perovskite [33]. The PS solution was prepared by adding PS into toluene (0-1.5wt\%) and stirring at $40^{\circ} \mathrm{C}$ and $500 \mathrm{rpm}$ for $12 \mathrm{~h}$. $10 \mu \mathrm{L}$ of the perovskite precursor solution heated at $70^{\circ} \mathrm{C}$ was dropped on the carbon counter electrode of the solar cell prepared above, spin-coated at $3000 \mathrm{rpm}$ for $20 \mathrm{~s}$, and then heated at $100^{\circ} \mathrm{C}$ for $40 \mathrm{~min}$. Then, $0.1 \mathrm{~mL}$ of PS solution was subsequently dropped on a perovskite-coated carbon electrode, spincoated at $3000 \mathrm{rpm}$ for $10 \mathrm{~s}$ and then dried at $40^{\circ} \mathrm{C}$ for $10 \mathrm{~min}$. The control device was prepared by treating toluene without PS as above. In the following section, the PM-PSC treated with constant PS concentration ( $x$ wt\%) were denoted as PM-PSCs/PS-x.

The samples for the optical absorption, morphology and crystallinity of PS-treated perovskite films were prepared under the same conditions of spin-coating on the glass $/ \mathrm{ZrO}_{2}$ structures without carbon layer, which were labeled as PS-x.

All device fabrication processes were performed under atmospheric conditions.

\subsection{Characteristics}

The optical absorption and crystal state of perovskite films were measured using UV-Visible absorption spectroscopy (DU 730) and x-ray diffraction spectroscopy (XRD, Cu Ka, 40 kV, Smartlab ) respectively. Crystal size and surface morphology were investigated using scanning electron microscopy (SEM, JS6610A). The charge transfer and charge recombination characteristics in PM-PSCs/PS-x were investigated by obtaining an electrochemical impedance spectra (EIS) using an electrochemical measurement system (CHI604E). EIS were recorded in frequency domain $0.1-10^{5} \mathrm{~Hz}$, under the simulated AM1.5G illumination and the open circuit condition. The conductivity evaluation of the PS treated carbon 
separated by $5 \mathrm{~mm}$ in width, coated the carbon layer on it, penetrated the perovskite precursor solution, crystallized, and subsequently treated PS solution on it. Using an electrochemical analyzer (Chi604E), the conductivity of the carbon layer was estimated by measuring a linear-sweep voltammetry from $-0.5 \mathrm{~V}$ to $0.5 \mathrm{~V}$. Current density-voltage curves were recorded using CHI604E by reversible scanning at a scanning rate of $100 \mathrm{mV} / \mathrm{s}$ under the simulated AM1.5G illumination. All the photoelectric characteristics were measured at an active area of $0.1 \mathrm{~cm}^{2}$.

\section{Results And Discussion}

The structure and energy levels of PM-PSCs are shown in Fig. 1. The $\mathrm{TiO}_{2}$ compact layer acts as an electron-collection and hole-blocking layer, and the $\mathrm{TiO}_{2}$ layer acts as an electron-transport layer, the $\mathrm{ZrO}_{2}$ layer as a space layer separating the carbon layer and the $\mathrm{TiO}_{2}$ layer. The appropriate arrangement of energy levels of $\mathrm{TiO}_{2}, \mathrm{CH}_{3} \mathrm{NH}_{3} \mathrm{Pbl}_{3-x}$, and carbon layers enables the separation and transport of photoinduced electrons and holes efficiently [32].

To investigate the effect of PS on the photoelectric conversion characteristics of PM-PSCs, different concentrations of PS solution were applied to PM-PSCs and PCE were measured. The photocurrentvoltage characteristics $(\mathrm{J}-\mathrm{V})$ under the simulated AM1.5G illumination $\left(100 \mathrm{~mW} / \mathrm{cm}^{2}\right)$ are shown in Fig. 2. As shown in Fig. 2, the short-circuit current density (Jsc), open-circuit voltage (Voc), and fill-factor (FF) of PM-PSCs/PS-0.5, PM-PSCs/PS-1 and PM-PSCs/PS-1.5 tended to be increased than PM-PSCs/PS-0. Jscs of PM-PSCs/PS-0.5, PM-PSCs/PS-1, and PM-PSCs/PS-1.5 were not significantly different, but differences were observed in Voc and FF, and the Voc and FF of PM-PSCs/PS-1 were the highest among them. The improvement of PCE in PM-PSCs/PS-1 is may be due to the reduced charge recombination and facilitated charge transfer at the interfaces of PM-PSCs [31]. However, in the case of high PS concentration, charge transfer at the interfaces such as perovskite/carbon and perovskite/ $\mathrm{TiO}_{2}$ interfaces can be suppressed due to the insulating properties of PS. As a result, the photoelectric characteristics of PM-PSCs/PS-1.5 can be lower than PM-PSCs/PS-1.

Figure 3 shows the statistical results of Jsc, Voc, FF, and PCE of PM-PSCs/PS- 0 and PM-PSCs/PS-1, while the detailed parameters are collected in Table 1. As shown in Fig. 3 and Table 1, the average values of Jsc, Voc, FF, and PCEs in PM-PSCs/PS-1 improved from 22.31(PM-PSCs/PS-0) to $22.72 \mathrm{~mA} / \mathrm{cm}^{2}$, 0.9 (PM-PSCs/PS-0) to 0.95 V, 0.6 (PM-PSCs/PS-0) to 0.65 and 11.31 (PM-PSCs/PS-0) to $14.03 \%$, respectively. 
Table 1

Photovoltaic characteristic of PM-PSCs prepared by treatment with different concentration of PS solution

\begin{tabular}{|lllll|}
\hline Devices & Jsc $\left(\mathrm{mA} / \mathrm{cm}^{2}\right)$ & Voc $(\mathrm{V})$ & $\mathrm{FF}$ & $\mathrm{PCE}(\%)$ \\
\hline PM-PSC/PS-0 & $22.31 \pm 0.35$ & $0.89 \pm 0.02$ & $0.57 \pm 0.02$ & $11.31 \pm 0.35$ \\
\hline PM-PSC/PS-0.5 & $22.65 \pm 0.33$ & $0.90 \pm 0.01$ & $0.60 \pm 0.01$ & $12.23 \pm 0.37$ \\
\hline PM-PSC/PS-1 & $22.72 \pm 0.27$ & $0.95 \pm 0.01$ & $0.65 \pm 0.01$ & $14.03 \pm 0.41$ \\
\hline PM-PSC/PS-1.5 & $22.69 \pm 0.34$ & $0.92 \pm 0.01$ & $0.62 \pm 0.01$ & $12.94 \pm 0.39$ \\
\hline
\end{tabular}

We performed measurements under forward $(F)$ and reverse $(R)$ scanning conditions using PM-PSCs/PS-1 and PM-PSCs/PS-0 to investigate the effect of PS on current-voltage hysteresis (Fig. 4). The hysteresis index $\left(\mathrm{HI}=\left(\mathrm{PCE}_{\text {reverse }}-\mathrm{PCE}_{\text {forward }}\right) / \mathrm{PCE}_{\text {forward }}\right)$ of the PM-PSCs/PS-0 and PM-PSCs/PS- 1 were $2.6 \%$ and $3.4 \%$, respectively. The HI of PM-PSCs/PS-1 was not significantly different from the PM-PSCs/PS-0, which is believed to be due to the high dependence of current-voltage hysteresis of PM-PSCs with the $\mathrm{TiO}_{2}$ compact layer acting as electron-collector layer [34]. In our case, the PS treatment did not affect the current-voltage hysteresis characteristics, because the preparation conditions of $\mathrm{TiO}_{2}$ compact layers in all devices were identical.

We performed UV-Vis spectroscopy to investigate the effect of PS treatment on the optical absorption spectrum of perovskite film (Fig. 5). As shown in Fig. 5 , the optical absorption in the PS- 0.5 and PS-1 wavelength range from 350 to $760 \mathrm{~nm}$ increased compared to PS-0, but the optical absorption in the PS1.5 decreased. As shown in Fig. 1s (supporting Information), considering that there is no change in the XRD intensity of the PS-treated perovskite and control films and that the optical absorption peak position at $745 \mathrm{~nm}$ wavelength in Fig. 5 does not change, it can be seen that PS treatment does not affect the composition of perovskite and does not affect the molar absorption coefficient of perovskite film [35].

We performed SEM measurements to further investigate the crystalline state of PS-1 with good optical absorption properties. Top-view SEM images of the perovskite films treated with different concentration of PS were shown in Fig. 6a-d. As shown in Fig. 6c, the perovskite agglomerates of PS-1 were obviously larger than the other samples, and in Fig. $6 \mathrm{~d}$ it is clear that the perovskite agglomerates were separated. In the PS-1.5 case, it is thought that the perovskite agglomerates can be separated from each other because the perovskite crystals are more strongly condensed by the contraction force caused by the polymerization of large amounts of PS. In the previous work reported that PS formed carbonium ions by interaction with $\mathrm{Pbl}_{2}$ with lewis acidity in perovskite precursors, and the cross-linking of macromolecular techniques by these carbonium ions resulted in slow crystallization of perovskite resulting in slow crystallization of perovskite [30]. In our case, the treatment mode of PS is different, but with the same mechanism as above, the agglomerate size of perovskite can be increased by PS. The UV-Vis spectra measured in the present study are shown to have a significant effect on the optical transmission of Loading [MathJax]/jax/output/CommonHTML/fonts/TeX/fontdata.js light reflection effects. Finally, it can be seen 
that the optical transmission pathway increases in the perovskite film of PS-1, which improves the optical absorption. However, PS-1.5 can be seen to decrease the roughness of the film and consequently decrease the light scattering effect due to the large amount of PS. As a result, the perovskite agglomerates in PS-1 become larger and the optical absorption can be increased as shown in Fig. 5 .

We performed conductivity of the carbon layers and electrochemical impedance spectra (EIS) measurements to investigate in detail the effect of PS on charge transfer and recombination in the PMPSCs. To investigate the effect of PS on the conductivity, we measured linear sweep voltammetry of the carbon layers (Fig. 7a). The conductivity of PS or perovskite covered carbon layes improved than pure carbon layer, but no difference of the conductivity of the perovskite covered carbon layers with and without PS. Through this result we found that PS did not affect the conductivity of the carbon layer.

EIS measurements were also performed under light irradiation of 1sun intensity and open circuit condition. The Nyquist curves and equivalent circuit model of PS treated PM-PSCs are shown in Fig. 7b and Fig. 7c respectively. As shown in Fig. 7b, two semicircles in high-frequency and low-frequency bands are clearly generated. The intersection point of the first high-frequency semicircle with real axis reflects the series resistance (Rs), and the high-frequency semicircle and the low-frequency semicircle reflects the charge transfer resistance $\left(R_{c t}\right)$ and charge recombination resistance $\left(R_{r e c}\right)$ in the PSCs, respectively [37]. We calculated $R s, R_{c t}$, and $R_{\text {rec }}$ using a simple equivalent circuit model (see inset in Fig. $7 b$ ). The results are shown in Table 2. The Rs of PM-PSCs/PS-1 and PM-PSCs/PS-0 was 33.7 and $34.1 \Omega$, respectively, but the $\mathrm{R}_{\mathrm{ct}}(8.9 \Omega)$ of PM-PSCs/PS-1 was less than PM-PSCs/PS-0 $(12.9 \Omega)$, whereas the $\mathrm{R}_{\text {rec }}(59.3 \Omega)$ of PM-PSCs/PS-1 was higher than PM-PSCs/PS-0 (22.1 $\Omega$ ). The corresponding Bode plots of the PM-PSCs with PS were shown in Fig. 2s (supporting Information), and the intensities of the peaks in the highfrequency and low-frequency regions were significantly difference with PS concentration. In the PMPSCs/PS-1, the lowest peak intensity in the high-frequency region and the highest peak intensity in the low-frequency region were shown. As a result, we can see that hole extraction at the perovskite/carbon interface of PM-PSCs/PS-1 is effectively promoted and the charge recombination at the interfaces is greatly reduced. In detail, because of the perovskite layer formation by low-temperature solution process, various defects may exist on the perovskite bulk and surface [38][39]. These defects can act as trapassisted recombination centers (Shockley-Read-Hall) and these defects allow free charge carriers to undergo non-radiative recombination [40][41]. These recombination centers would yield shorter the carrier lifetime. Therefore the decrease in charge transfer resistance in PM-PSCs/PS-1 and the increase in charge recombination resistance may be attributed to the passivation of the charge trap positions on the perovskite crystal surface and the better contact with perovskite and carbon layers by PS. Because perovskite material in PM-PSCs acts simultaneously as a photoabsorber and charge (electron and hole) transport, it is important to promote hole extraction and prevent charge recombination by favoring contact between perovskite with carbon layers. In PM-PSCs/PS-1, PS is expected to increase the size of perovskite agglomeration and improve the contact with the carbon layer, resulting in reduced charge transfer resistance and increased charge recombination resistance. As the charge transfer resistance decreases. charae iniection is imbroved to increase Jsc. and the charge recombination resistance Loading [MathJax]/jax/output/CommonHTML/fonts/TeX/fontdata.js 
increases, the leakage current decreases, resulting in improved Voc and FF. The charge transfer resistance also affects Voc and FF because it acts as a series resistance during charge transport [42]. Finally, the Nyquist results are in good agreement with the results of Fig. 2.

Table 2

Electrical resistance parameters obtained from

EIS data were measured under light irradiation

of 1 sun intensity and open circuit condition

\begin{tabular}{|llll|}
\hline Devices & $\mathbf{R s}(\Omega)$ & $\mathbf{R}_{\mathrm{ct}}(\boldsymbol{\Omega})$ & $\mathbf{R}_{\text {rec }}(\boldsymbol{\Omega})$ \\
\hline PM-PSC/PS-0 & 34.1 & 12.9 & 22.1 \\
\hline PM-PSC/PS-1 & 33.7 & 8.9 & 59.3 \\
\hline
\end{tabular}

We performed XRD spectra of perovskite films coated on glass incubated for 10 days at $60 \%$ relative humidity to investigate the effect of PS on the degradation of perovskite crystals by humidity (Fig. 8). As shown in Fig. 8, the PS treated perovskite film showed no diffraction peak corresponding to the (001) crystal face of $\mathrm{Pbl}_{2}$. As shown in Fig. S3, the water contact angles on the carbon electrode with and without perovskite were increased by PS, especially, the contact angle on the carbon electrode with perovskite was increased from $79.12^{\circ}$ to $87.01^{\circ}$ by PS treatment. As can be ssen in the Fig. S3(a, b), the contact angle on the carbon electrode with perovskite was smaller than that without perovskite and it would be associated with the residual perovskite in the carbon layer, which would react with water. It can be seen that PS is coated on the surface of perovskite crystals and the wettability of $\mathrm{H}_{2} \mathrm{O}$ on the perovskite grains was reduced to prevent the degradation of perovskite into $\mathrm{Pbl}_{2}$ by moisture[35].

We performed photostability test of maximum power-point tracking under $100 \mathrm{~h}$ continuous illumination of 1 sun intensity at $60 \%$ of relative humidity about the PS treated PM-PSCs without sealing. The results are shown in Fig. 9. The photostability test was carried out at keeping the substrate temperature of $25^{\circ} \mathrm{C}$. As shown in Fig. 9, Jsc, Voc, FF, and PCE after $100 \mathrm{~h}$ of operation in PM-PSCs/PS-0 maintained 77, 88, 92 and $63 \%$ of the initial values, respectively. However, in PM-PSCs/PS-1, Jsc, Voc, and FF maintained 94, 97 and $99 \%$ of the initial values, respectively, after $100 \mathrm{~h}$ of operation, while PCE was maintained at a higher level compared to PM-PSCs/PS-0, with $90 \%$ of the initial values. Through this result, we can see that PS effectively prevents the corrosion of perovskite even under operating conditions. Improvement of this photostability is because hydrophobic PS is coated on the perovskite crystal surface to effectively prevent humidity penetration and consequently greatly inhibit humidity-induced photodegradation.

\section{Conclusion}

The effect of PS on the efficiency and stability of PM-PSCs prepared by treatment on the carbon layer was investigated. The effect of PS on the efficiency and stability of PM-PSCs prepared by treatment on the carbon electrode was investigated. PS can change the agglomeration size of perovskite crystals and increase the optical transmission length. The PS treatment did not have a significant effect on the

Loading [MathJax]/jax/output/CommonHTML/fonts/TeX/fontdata.js er at the PM-PSCs interfaces, and reducing 
charge recombination, thereby improving the photoelectric conversion efficiency. In addition, as PS was coated on the perovskite crystal surface and increased the corrosion stability against moisture, the PMPSCs without sealing maintained $90 \%$ of the initial efficiency even after $100 \mathrm{~h}$ operation under light conditions of 1 sun intensity. PS is an effective material that can improve the performance and stability of PM-PSCs.

\section{Declarations}

\section{Notes}

Declarations of interest: none

\section{Acknowledgements}

\section{Electronic Supplementary material}

\section{References}

1. O. Morton, Nature 443, 19 (2006)

2. A. Kojima, K. Teshima, Y. Shirai, T. Miyasaka, J. Am. Chem. Soc. 131, 6050 (2009)

3. E. Raphael, M.N. Silva, R. Szostak, M.A. Schiavon, A.F. Nogueira, Quim. Nova 41, 61 (2018)

4. http://www.nrel.gov/pv/cell-efficiency.html

5. C. Wehrenfennig, G.E. Eperon, M.B. Johnston, H.J. Snaith, L.M. Herz, Adv. Mater. 26, 1584 (2014)

6. Q.F. Dong, Y.J. Fang, Y.C. Shao, P. Mulligan, J. Qiu, L. Cao, J.S. Huang, Science 347, 967 (2015)

7. Q. Chen, N. De Marco, Y. Yang, T.B. Song, C.C. Chen, H.X. Zhao, Z.R. Hong, H.P. Zhou, Y. Yang, Nano Today 10, 355 (2015)

8. X. Li, D. Bi, C. Yi, J.D. Decoppet, J. Luo, S.M. Zakeeruddin, A. Hagfeldt, M. Gratzel, Science 353, 58 (2016)

9. D.P. McMeekin, G. Sadoughi, W. Rehman, G.E. Eperon, M. Saliba, M.T. Horantner, A. Haghighirad, N. Sakai, L. Korte, B. Rech, M.B. Johnston, L.M. Herz, H.J. Snaith, Science 351, 151 (2016)

10. Z.R. Zhao, F.D. Gu, H.X. Rao, S.Y. Ye, Z.W. Liu, Z.Q. Bian, C.H. Huang, Adv. Energy Mater. 9, 1802671 (2018)

11. C.T. Zuo, A. Scully, D. Yak, W. L. Tan, X.C. Jiao, C.R. McNeill, D.C. Angmo, L.M. Ding, M. Gao, Adv. Energy Mater. 9, 1803258 (2019)

12. G. Grancini, M.K. Nazeeruddin, Nat. Rev. Mater. 4, 4 (2019)

13. Z.Y. Fu, M. Xu, Y.S. Sheng, Z.B. Yan, J. Meng, C.H. Tong, D. Li, Z.N. Wan, Y. Ming, A.N. Mei, Y. Hu, Y.G. Rong, H.W. Han, Adv. Funct. Mater. 29, 1809129 (2019)

14. H.J. Snaith, A. Abate, J.M. Ball, G.E. Eperon, T. Leijtens, N.K. Noel, S.D. Stranks, J.T. Wang, K. Whirierhnweki W 7hann I Phve Chem I ott 51511 (2014) 
15. I. Zimmermann, P. Gratia, D. Martineau, G. Grancini, J.N. Audinot, T. Wirtz, M.K. Nazeeruddin, J. Mater. Chem. A 7, 8073 (2019)

16. P.Y. Liu, W. Wang, S.M. Liu, H.G. Yang, Z.P. Shao, Adv. Energy Mater. 9, 1 (2019)

17. F. Hao, C.C. Stoumpos, D.H. Cao, R.P.H. Chang, M.G. Kanatzidis, Nat. Photonics 8, 489 (2014)

18. H.Y. Zhang, R. Li, W.W. Liu, M. Zhang, M. Guo, Int. J. Min. Met. Mater. 26, 387 (2019)

19. H.Y. Fu, Sol. Energ. Mat. Sol. C. 193, 107 (2019)

20. Y.H. Deng, E. Peng, Y.C. Shao, Z.G. Xiao, Q.F. Dong, J.S. Huang, Energ. Environ. Sci. 8, 1544 (2015)

21. J. Wei, C.L. Shi, Y.C. Zhao, W.K. Zhou, H. Li, R. Fu, D.P. Yu, Q. Zhao, Sci. China Mater. 59, 769 (2016)

22. W. Zi, Z.W. Jin, S.Z. Liu, B.M. Xu, J. Energy Chem. 27, 971 (2018)

23. F. Di Giacomo, S. Shanmugam, H. Fledderus, B.J. Bruijnaers, W.J.H. Verhees, M.S. Dorenkamper, S.C. Veenstra, W.M. Qiu, R. Gehlhaar, T. Merckx, T. Aernouts, R. Andriessen, Y. Galagan, Sol. Energ. Mat. Sol. C. 181, 53 (2018)

24. Z.P. Shao, Z.W. Wang, Z.P. Li, Y.P. Fan, H.G. Meng, R.R. Liu, Y. Wang, A. Hagfeldt, G.L. Cui, S.P. Pang, Angew. Chem. Int. Edit. 58, 5587 (2019)

25. L.L. Deng, K. Wang, H.J. Yang, H.M. Yu, B. Hu, J. Phys. D Appl. Phys. 51, 475102 (2018)

26. B. Mckenna, J.R. Troughton, T.M. Watson, R.C. Evans, Rsc Adv. 7, 32942 (2017)

27. J. He, C.F. Ng, K.Y. Wong, W.F. Liu, T. Chen, Chempluschem 81, 1292 (2016)

28. Y.C. Zhao, J. Wei, H. Li, Y. Yan, W.K. Zhou, D.P. Yu, Q. Zhao, Nat. Commun. 7, 1 (2016)

29. J.W. Wei, F.R. Huang, S.N. Wang, L.Y. Zhou, P. Jin, Y.L. Xin, Z. Cai, Z.D. Yin, Q. Pang, J.Z. Zhang,

Chemnanomat 4, 649 (2018)

30. R. Saraf, V. Maheshwari, ACS Appl. Energy Mater. 2, 2214 (2019)

31. M. Chen, M.Z. Mokhtar, E. Whittaker, Q. Lian, B. Hamilton, P. O'Brien, M.N. Zhu, Z.X. Cui, S.A. Haqued, B.R. Saunders, Nanoscale 9, 10126 (2017)

32. B. Kim, S.G. Ko, K.S. Sonu, J.H. Ri, U.C. Kim, G.I. Ryu, J. Electron. Mater. 47, 6266 (2018)

33. M.D. Xiao, F.Z. Huang, W.C. Huang, Y. Dkhissi, Y. Zhu, J. Etheridge, A. Gray-Weale, U. Bach, Y.B. Cheng, L. Spiccia, Angew. Chem. Int. Edit. 53, 9898 (2014)

34. Y.G. Rong, Y. Hu, S. Ravishankar, H.W. Liu, X.M. Hou, Y.S. Sheng, A.Y. Mei, Q.F. Wang, D.Y. Li, M. Xu, J. Bisquert, H.W. Han, Energ. Environ. Sci. 10, 2383 (2017).

35. H.Y. Zhang, J.J. Shi, L.F. Zhu, Y.H. Luo, D.M. Li, H.J. Wu, Q.B. Meng, Nano Energy 43, 383 (2018)

36. Q. Wang, Q.F. Dong, T. Li, A. Gruverman, J.S. Huang, Adv. Mater. 28, 6734 (2016)

37. J.P. Correa-Baena, S.H. Turren-Cruz, W. Tress, A. Hagfeldt, C. Aranda, L. Shooshtari, J. Bisquert, A. Guerrero, Acs Energy Lett. 2, 681 (2017)

38. Y.Wang, H.Y. Wang, M. Yu, L.M. Fu, Y. Qin, J.P. Zhang, X.C. Ai, Phys. Chem. Chem. Phys. 17, 29501 (2015)

39. C.F. Han, K. Wang, X.X. Zhu, H.M. Yu, X.J. Sun, Q. Yang, B. Hu, J. Phys. D Appl. Phys. 51, 95501 
40. G.J.A.H. Wetzelaer, M. Scheepers, A.M. Sempere, C. Momblona, J. Avila, H.J. Bolink, Adv. Mater. 27, 1837 (2015)

41. V. Sarritzu, N. Sestu, D. Marongiu, X.Q. Chang, S. Masi, A. Rizzo, S. Colella, F. Quochi, M. Saba, A. Mura, G. Bongiovanni, Sci. Rep. 7, 44629 (2017)

42. P. Yadav, M.H. Alotaibi, N. Arora, M.I. Dar, S.M. Zakeeruddin, M. Gratzel, Adv. Funct. Mater. 28, $1706073(2018)$

\section{Figures}



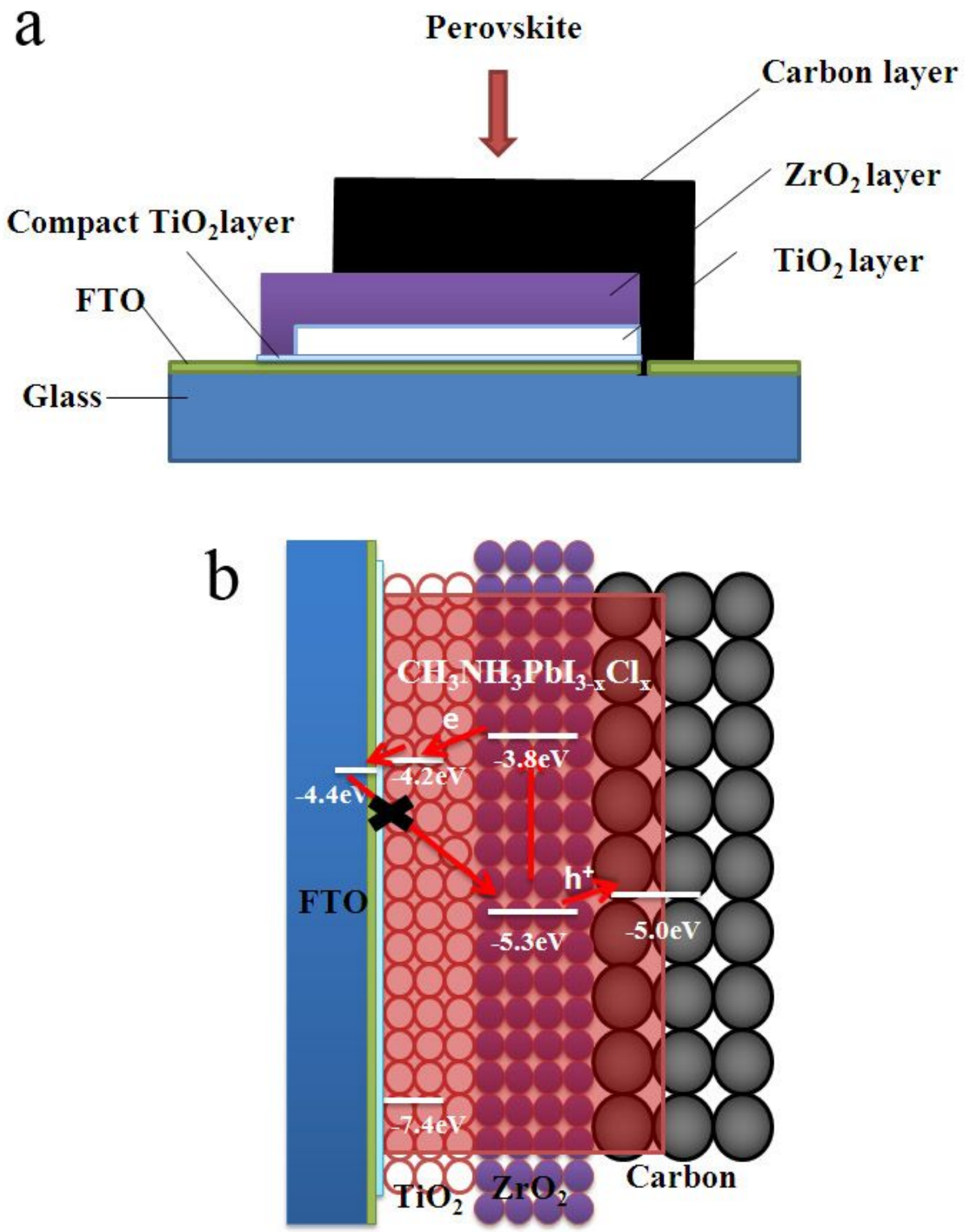

Figure 1

a Schematic structure of the PM-PSCs. b Energy level diagram of PM-PSCs 


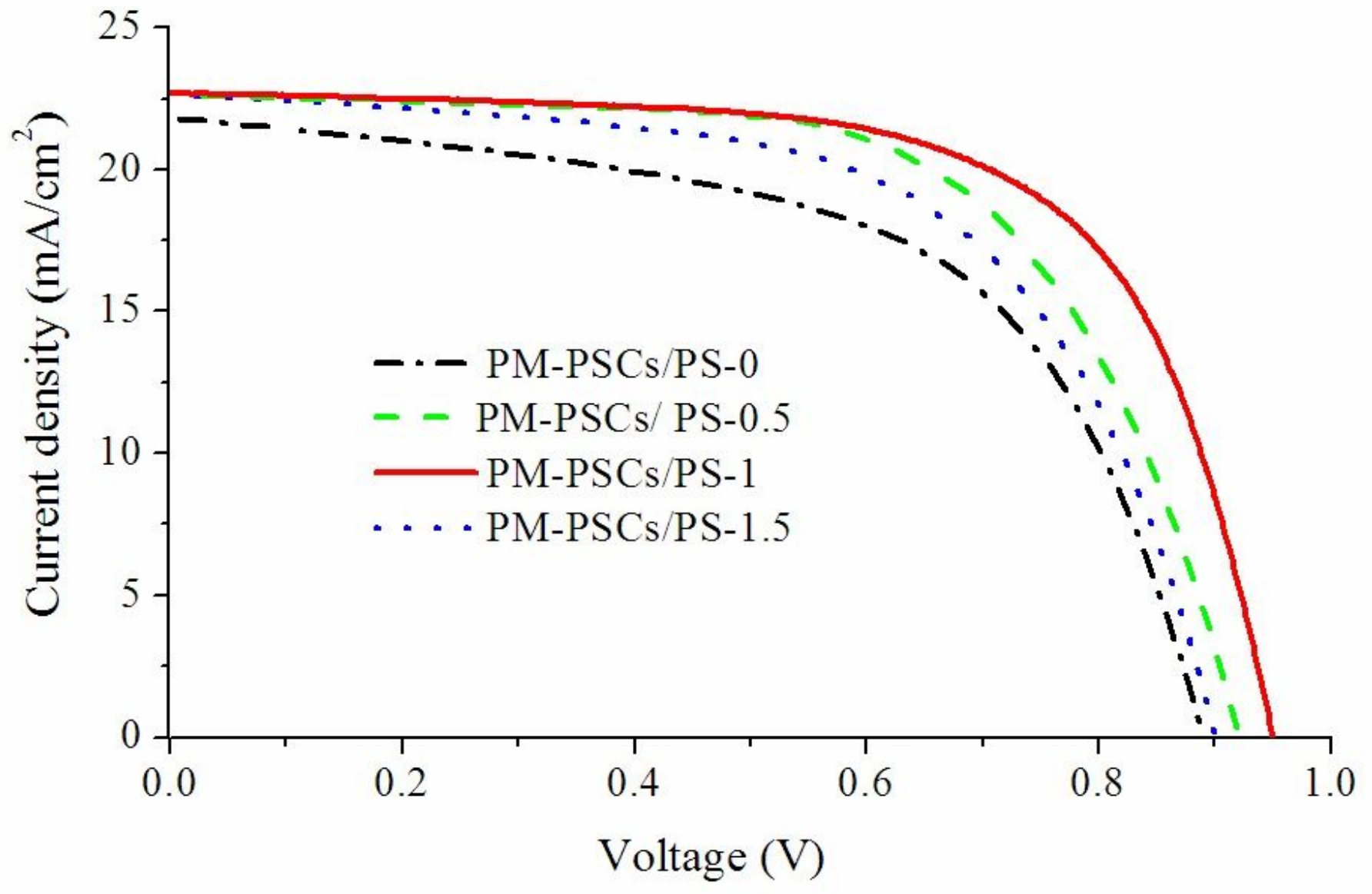

Figure 2

$\mathrm{J}-\mathrm{V}$ curves of PM-PSCs prepared by treatment with different concentration of PS solution 

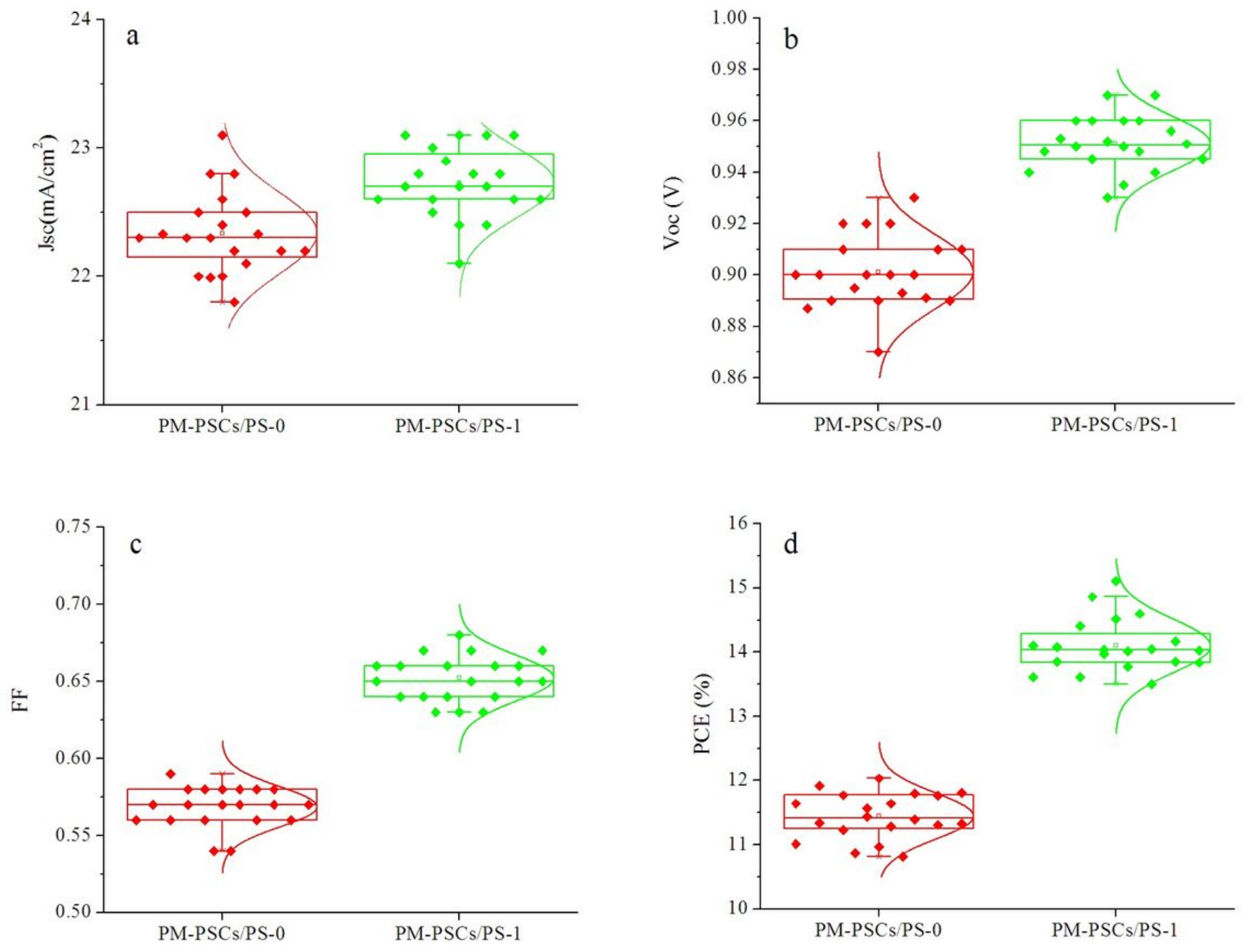

\section{Figure 3}

Statistical comparisons of photovoltaic characteristics in PM-PSCs/PS-0 and PM-PSCs/PS-1 


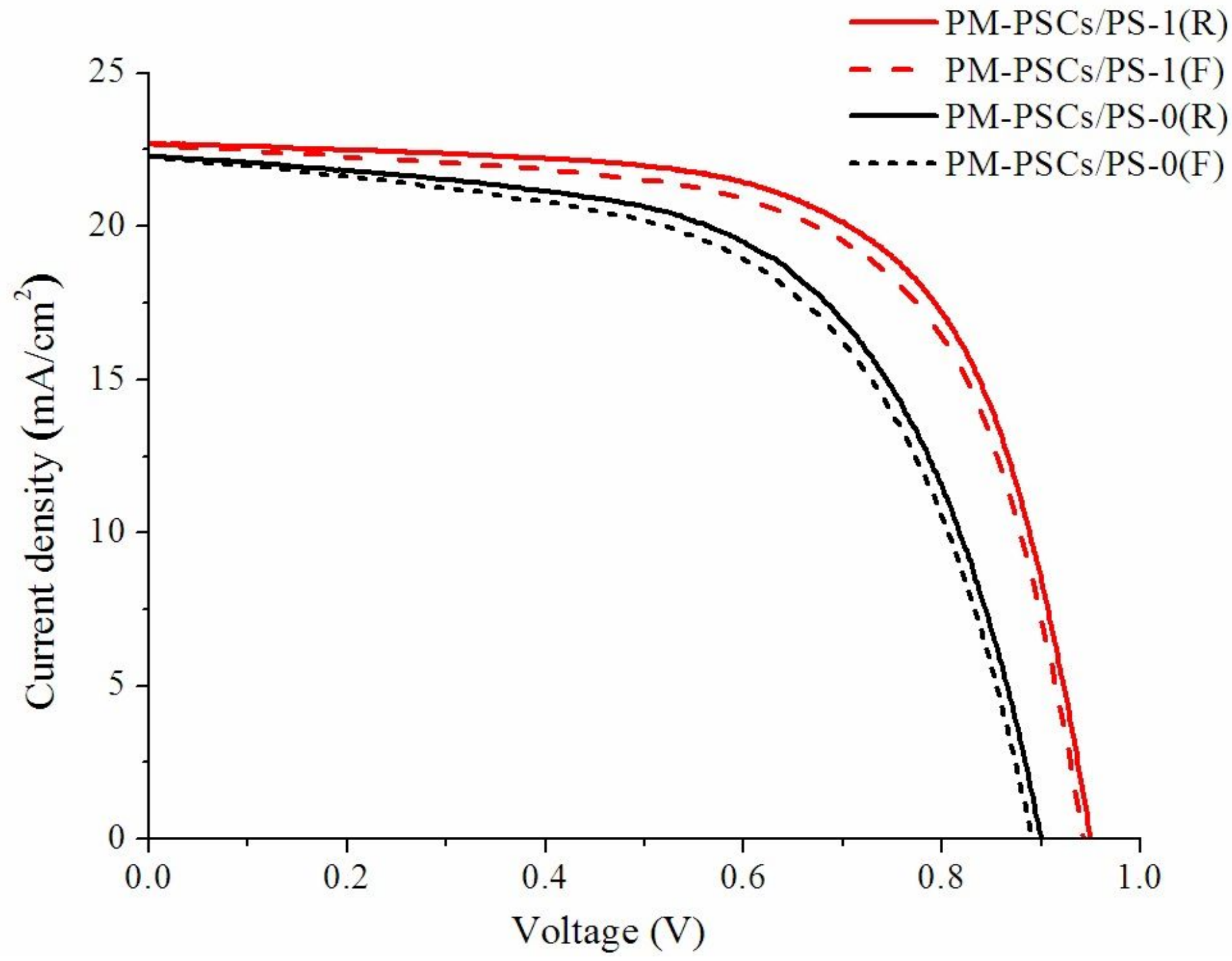

Figure 4

Current - voltage hysteresis of PM-PSCs/PS-1 and PM-PSCs/PS-0 


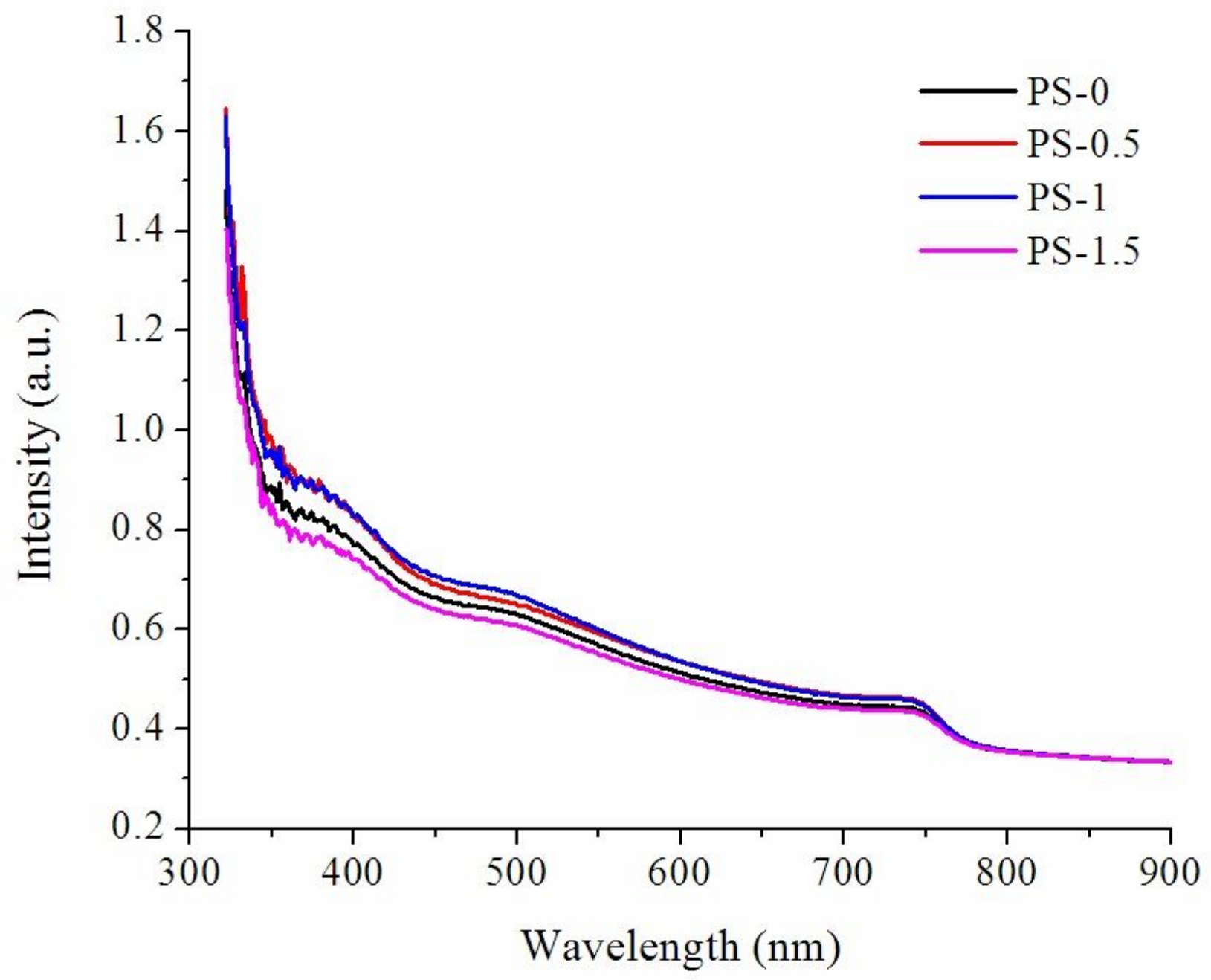

Figure 5

Optical absorption spectrum of perovskite film on the PS concentration 

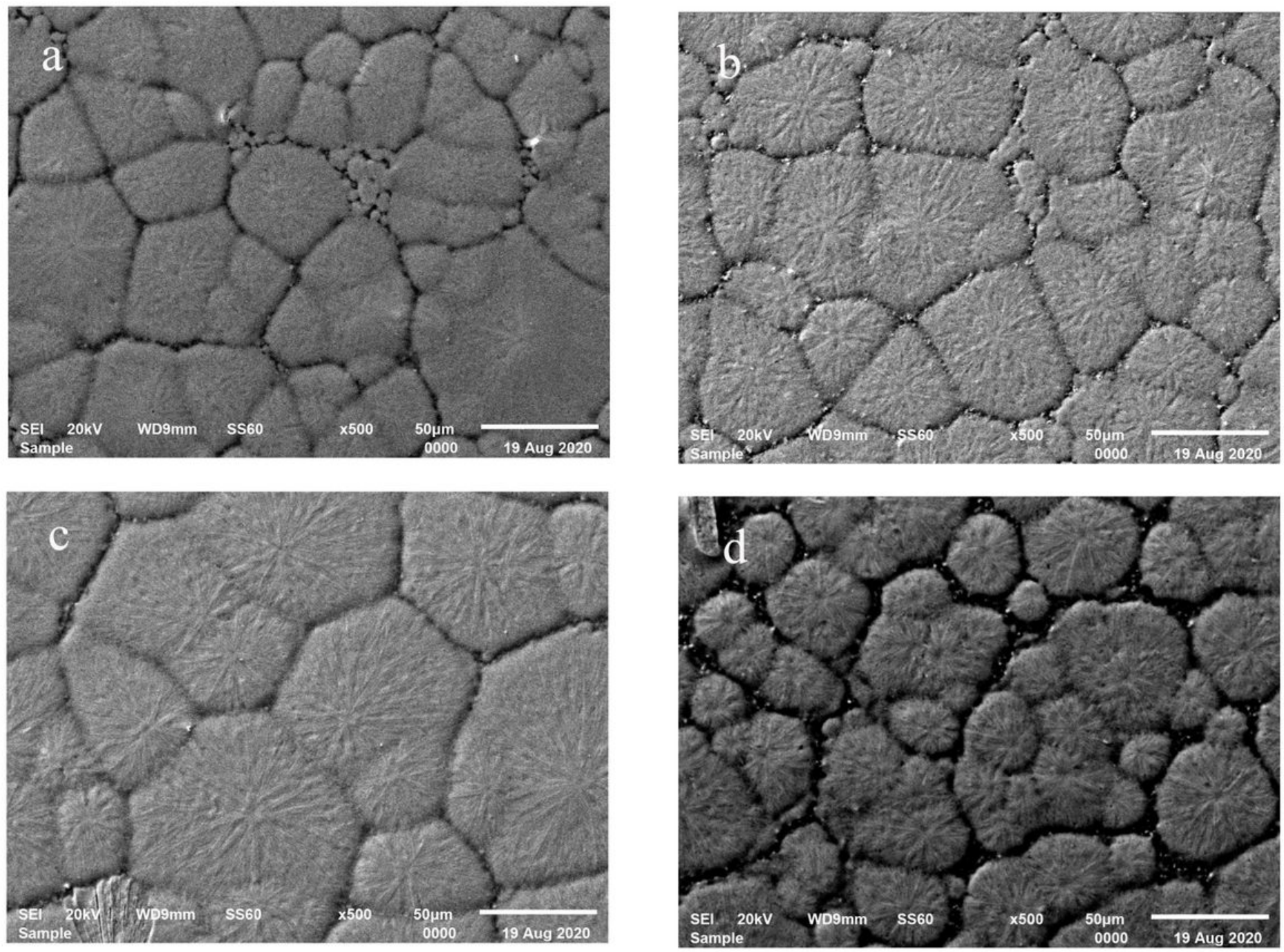

\section{Figure 6}

SEM images of the perovskite film surfaces treated with different concentration of PS a: PS-0, b: PS- 0.5 , c: PS-1, d: PS-1.5 

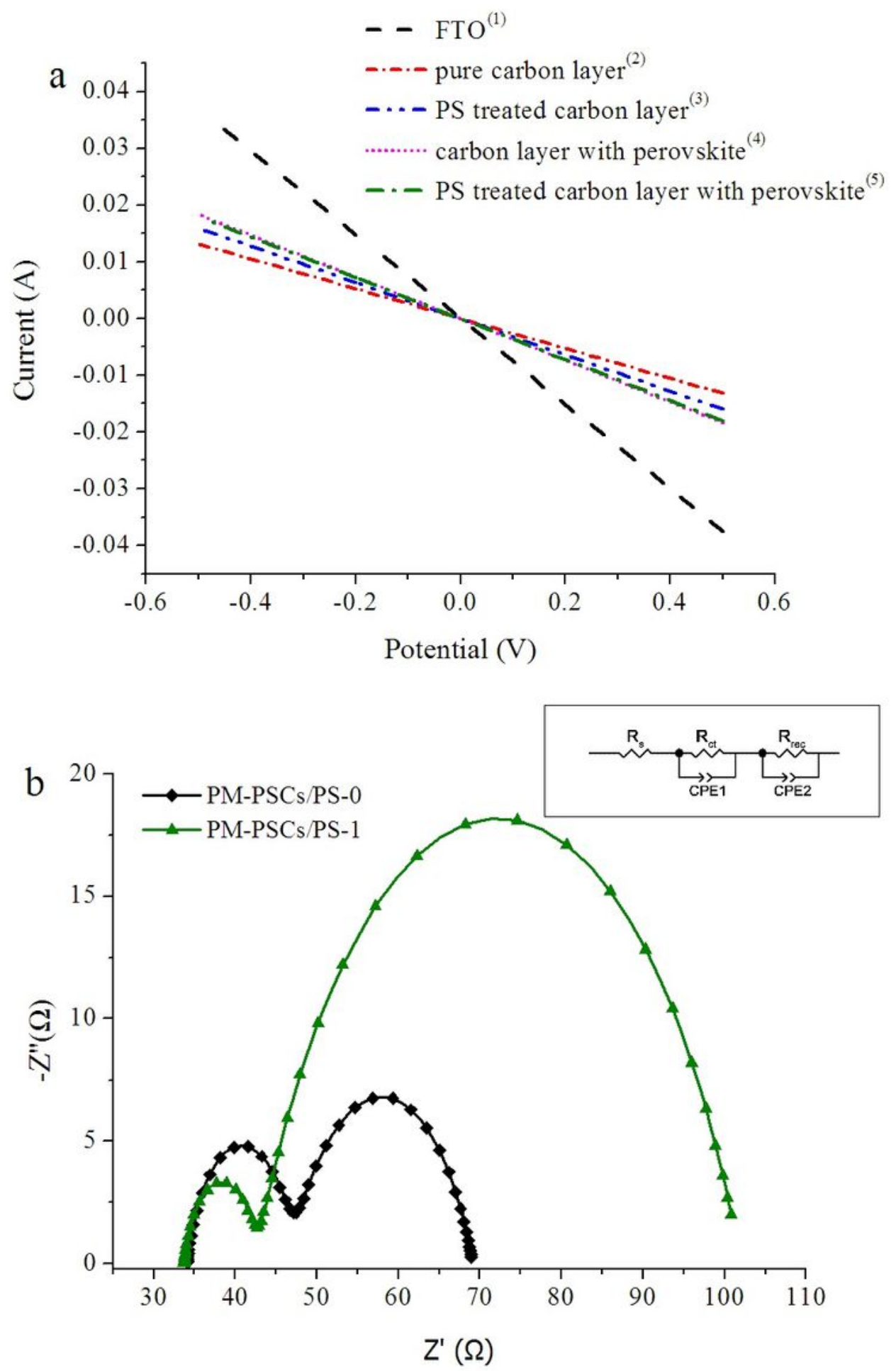

Figure 7

a Linear sweep voltammetry plot. b Nyquist curves of the PM-PSCs/PS-1 and PM-PSCs/PS-0 over the frequency range of $0.1 \mathrm{~Hz}$ to $105 \mathrm{~Hz}$ under simulated $\mathrm{AM} 1.5 \mathrm{G}(100 \mathrm{~mW} / \mathrm{cm} 2)$. c equivalent circuit model 1: pure FTO; 2: detached FTO/carbon; 3: detached FTO/carbon/PS; 4: detached FTO/carbon/perovskite; 5: detached FTO/carbon/perovskite/PS 


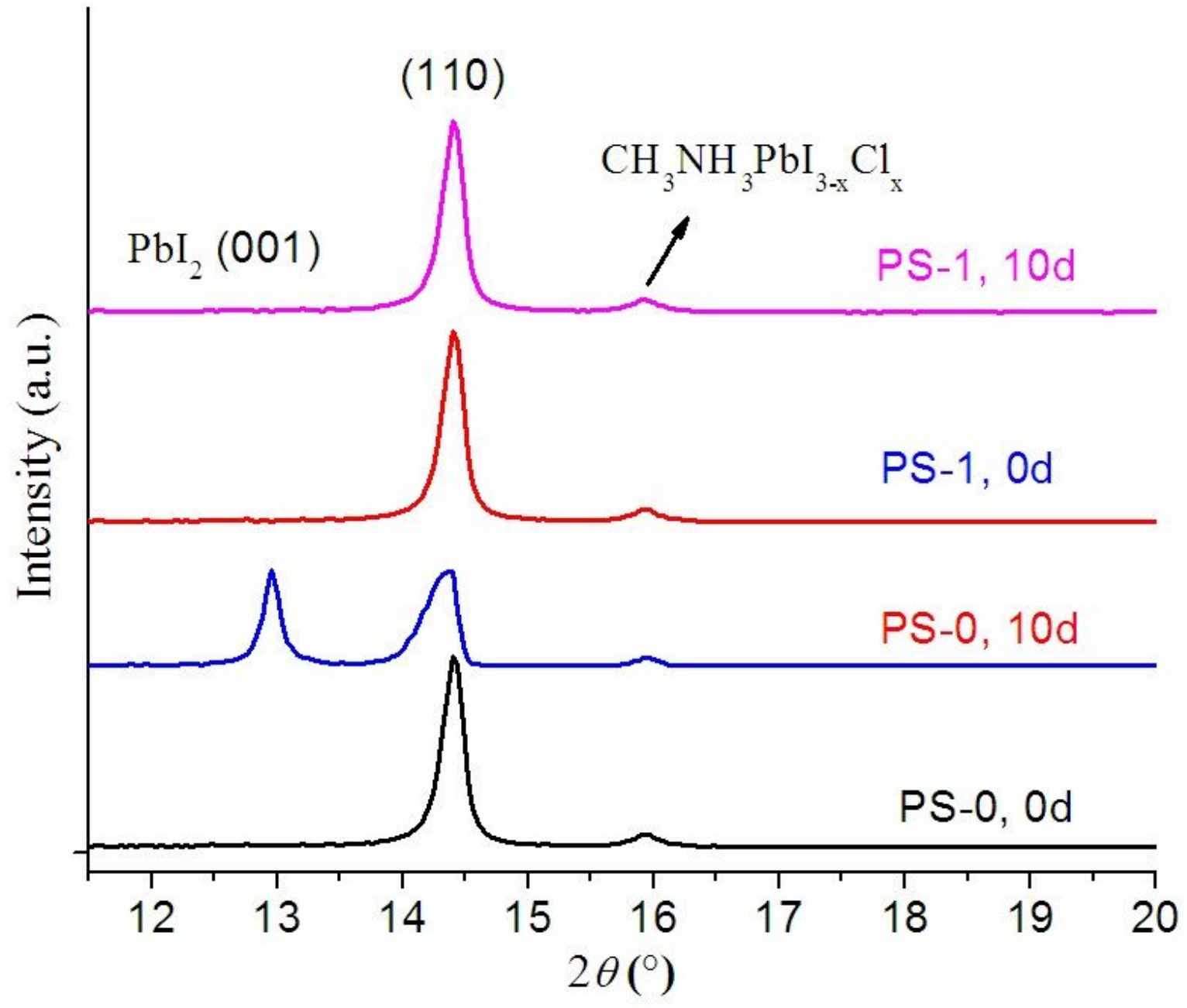

Figure 8

XRD spectra of perovskite films coated on glass incubated for 10 days at $60 \%$ relative humidity 

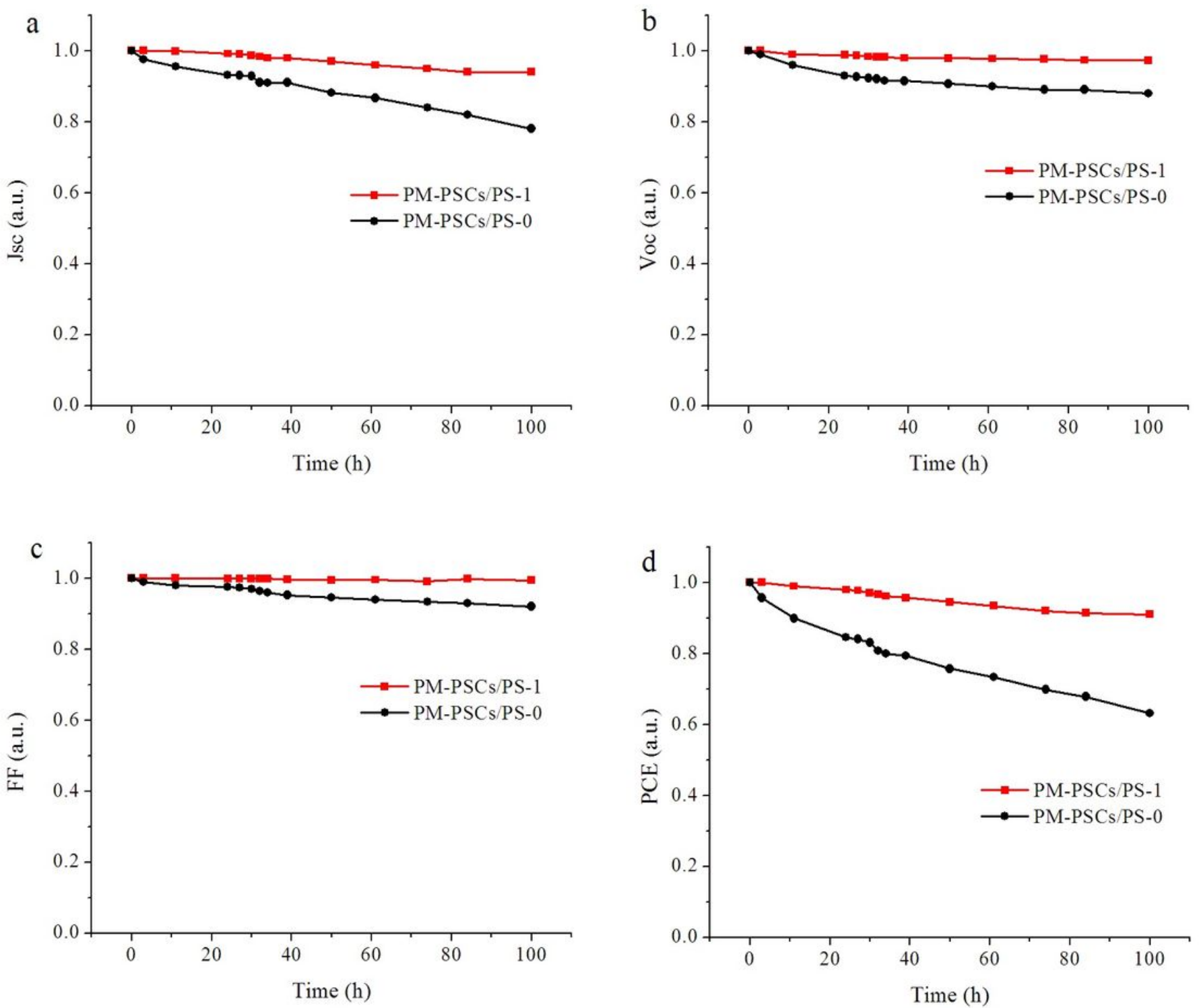

\section{Figure 9}

photostability test of maximum power-point tracking under $100 \mathrm{~h}$ continuous illumination of 1 sun intensity at $60 \%$ of relative humidity about the PS treated PM-PSCs without sealing 